\title{
Pengaruh Waktu Dimulainya Pendinginan Selama Penetasan Terhadap Daya Tetas Telur Itik Persilangan Cihateup Alabio
}

\author{
The Effect of Start Cooling During Incubation on Cross Cihateup Alabio \\ Duck Eggs Hatchability \\ Diniati $^{1)}$, Rukmiasih ${ }^{2)}$ \& R. Afnan ${ }^{2)}$ \\ 1) Mahasiswa Departemen Ilmu Produksi dan Teknologi Peternakan, Fakultas Peternakan, \\ Institut Pertanian Bogor \\ ${ }^{2)}$ Departemen Ilmu Produksi dan Teknologi Peternakan, Fakultas Peternakan, \\ Institut Pertanian Bogor \\ Jln. Agatis, Kampus IPB Dramaga, Bogor 16680
}

\begin{abstract}
Duck eggs have lower hatchability because they have higher risk of embryo mortality due to a longer incubation than chicken eggs. This study was designed to obtain the proper of start cooling during artificial incubation to improve duck eggs hatchability and hatching weight. Eggs of cihateup alabio duck were obtained from Balai Penelitian Ternak (Balitnak) Ciawi. Eggs were collected weekly in 5 different times. Total egg collected was 419 eggs. Incubated eggs were sprayed and cooled for 0.25 $h$ at room temperature for 2 times a day in setter period. This study used randomized block design and 3 treatments of starting cooling time of egg. Observed variables were egg weight, fertility, hatchability, embryo mortality and hatching weight. Cooling eggs at different times during the setter period did not affect to hatchability. Highest hatchability was obtained on Days 17. The start cooling significantly was affected the hatching weight.
\end{abstract}

Keywords: cihateup alabio eggs, cooling, hatchability, start time

\section{PENDAHULUAN}

Itik lokal yang telah lama dikem-bangkan masyarakat sebagai petelur kini sudah banyak dimanfaatkan juga sebagai penghasil daging. Populasi itik menurut DPKH (2012) yaitu 46.989.522 ekor, sedangkan ayam ras pedaging mencapai 1.266.902.718 ekor dan ayam ras petelur sebesar 130.539.437 ekor. Produktivitas itik lokal di masyarakat masih rendah, sehingga perlu adanya peningkatan mutu genetik seperti persilangan. Persilangan itik jantan cihateup dengan betina alabio (CA) yang telah dilakukan Matitaputty (2012) menunjukkan sifat daya tetas telur yang tinggi dan kematian embrio yang rendah daripada persilangan jantan alabio dengan betina cihateup (AC).

Rendahnya daya tetas telur itik daripada telur ayam menjadi per-masalahan utama dalam produksi bibit itik untuk memenuhi permintaan daging unggas. Telur itik memiliki karakteristik seperti bobot, panjang, lebar dan pori-pori kerabang yang berbeda dengan telur ayam. Waktu penetasan telur itik selama 28 hari berpengaruh terhadap perkembangan embrio yang berbeda dengan telur ayam yang hanya 21 hari. Perkembangan embrio akan menghasil-kan panas akibat proses metabolisme yang semakin meningkat selama proses penetasan. Kecepatan metabolisme embrio berperan penting dalam keberhasilan penetasan telur itik (Harun et al. 2001).

Kelebihan panas yang dihasilkan metabolisme embrio dan mesin tetas selama penetasan akan menyebabkan stres panas pada embrio yang dapat meningkatkan kematian embrio dan menurunkan daya tetas telur itik. Telur itik membutuhkan kelembaban yang lebih tinggi selama penetasan diban-dingkan telur ayam (Kortlang 1985).

Kecepatan metabolisme energi meningkat seiring dengan perkem-bangan embrio di dalam telur. Produksi panas selama penetasan lebih dipe-ngaruhi oleh tahapan perkembangan embrio (Meijerhof 2009). Perlakuan pendinginan telur pada waktu mulai yang tepat diharapkan dapat mening-katkan daya tetas telur itik, sehingga produksi DOD meningkat.

\section{MATERI DAN METODE}

Pemeliharaan dan perkawinan itik jantan cihateup dengan itik betina alabio untuk menghasilkan telur CA dilakukan di Balai Penelitian Ternak (Balitnak), Ciawi. Penetasan telur dilakukan di Laboratorium Penetasan Telur, Bagian Produksi Ternak Unggas, Fakultas Peternakan, Institut Pertanian Bogor.

Materi yang digunakan adalah 419 butir telur tetas itik CA. Jumlah telur pada periode penetasan/minggu ke-1 sampai 5 secara berturut-turut 29, 71, 120, 87 dan 112 butir. Telur tetas diperoleh dari kawin alami persilangan itik jantan cihateup berumur 1 tahun yang berasal dari peternak 
asal Tasikmalaya, Jawa Barat dengan itik betina alabio berumur 1,5 tahun yang berasal dari Kalimantan Selatan. Rasio jantan dan betina yang digunakan adalah 4:15 dan dipelihara pada alas kandang litter.

Pakan yang diberikan bentuk crumble dengan kandungan protein $16 \%-17 \%$, energi metabolis $2600-2700$ $\mathrm{kkal} / \mathrm{kg}$ dan kandungan kalsium 3,5\%-4\%. Bahan lain yang digunakan adalah disinfektan rodalon, larutan klorin, $\mathrm{Na}_{2} \mathrm{CO}_{3}, \mathrm{KMnO}_{4}$ danformalin $40 \%$.

Mesin tetas dilengkapi dengan peralatan egg tray atau tempat telur tetas dengan kapasitas 80-100 butir telur dan bak air di bawah rak telur.

Peralatan lain yaitu termometer digital, termometer bola kering-bola basah, jangka sorong, alat candling, wadah untuk sanitasi dan fumigasi telur, timbangan digital dan stopwatch. Pendinginan telur menggunakan gelas ukur dan sprayer.

\section{Rancangan Percobaan}

Penelitian ini menggunakan rancangan acak kelompok (RAK) dengan perlakuan waktu dimulainya pendinginan yang berbeda yaitu hari ke-3 $(\mathrm{H} 3)$, hari ke-10 (H10) dan hari ke-17 (H17) telur berada di dalam mesin tetas. Perlakuan $\mathrm{H} 10$ dan $\mathrm{H} 17$ diberikan 5 kelompok periode penetasan, sedangkan $\mathrm{H} 3$ hanya 4 kelompok.

Model matematis yang digunakan sebagai berikut (Mattjik dan Sumertajaya 2002):

$$
\mathrm{Y}_{\mathrm{ij}}=\mu+\mathrm{K}_{\mathrm{i}}+\mathrm{P}_{\mathrm{j}}+\varepsilon_{\mathrm{ij}}
$$

\section{Keterangan:}

$\mathrm{Y}_{\mathrm{ij}} \quad=$ nilai pengamatan waktu pendinginan ke-i dan periode penetasan $\mathrm{ke}-\mathrm{j}$

$\mu \quad=$ rataan umum

$\mathrm{K}_{\mathrm{i}} \quad$ = pengaruh waktu pendinginan ke- $\mathrm{i}$

$\mathrm{P}_{\mathrm{j}} \quad=$ pengaruh periode penetasan ke-j

$\varepsilon_{\mathrm{ij}}=$ pengaruh acak pada waktu pendinginan ke-i periode penetasan $\mathrm{ke}-\mathrm{j}$

Daya tetas, bobot tetas dan persentase bobot tetas yang diperoleh dianalisis secara statistik dengan Analysis of Variance (ANOVA). Uji jarak berganda Duncan dilakukan jika data menghasilkan perbedaan antar jenis perlakuan. Peubah lain seperti bobot, indeks, fertilitas telur dan kematian embrio dianalisis deskriptif.

Peubah yang diamati pada penelitian ini adalah bobot telur, lebar dan panjang telur, fertilitas, daya tetas, kematian embrio dan bobot tetas. Bobot telur ditimbang sebelum telur dimasukkan ke dalam mesin tetas. Fertilitas merupakan persentase telur yang menunjukkan adanya perkem-bangan embrio dari jumlah telur masuk ke dalam mesin tetas. Daya tetas adalah persentase telur yang menetas dari jumlah telur yang fertil. Kematian embrio dihitung dari persentase embrio yang mati selama proses penetasan. Bobot tetas DOD diukur setelah bulunya kering pasca menetas.

\section{HASIL DAN PEMBAHASAN}

Karakteristik Telur

Karakteristik telur CA pada penelitian ini meliputi bobot, indeks dan fertilitas telur. Telur berukuran seragam akan menghasilkan daya tetas yang lebih baik dibandingkan yang ber-variasi. Harun et al. (2001) menyatakan tingginya kematian embrio disebabkan variasi ukuran telur yang ditetaskan karena perbedaan laju metabolisme dan evaporasi di dalam mesin tetas.

\section{Bobot Telur}

Telur itik CA yang digunakan memiliki bobot $69,21 \pm 4,81 \mathrm{~g}$ (Tabel 1). Bobot telur CA pada penelitian Matitaputty et al. (2012) sebesar 63,06 g. Bobot telur CA yang diperoleh lebih berat disebabkan umur induk yang digunakan lebih tua. Induk alabio pada penelitian ini berumur 18 bulan, sehingga semakin tua umur induk akan meningkatkan bobot induk dan bobot telur yang dihasilkan. Bobot telur CA baik pada periode penetasan maupun perlakuan termasuk dalam kisaran bobot telur yang baik ditetaskan, yaitu 65-75 g dengan bentuk normal (Kortlang 1985).

\section{Indeks Telur}

Indeks telur merupakan persentase perbandingan lebar dengan panjang telur. Indeks telur CA pada penelitian ini berkisar 78\% (Tabel 2). Ukuran telur lebih dipengaruhi umur induk. Indeks telur yang lebih besar akan menampilkan telur yang lebih bulat, sedangkan indeks kecil telurnya lebih panjang. Induk yang tua cenderung menghasilkan telur yang bulat, sedangkan induk muda bentuk telurnya lonjong (Nurcahyo dan Widyastuti 1997).

\section{Fertilitas Telur}

Faktor-faktor yang mempengaruhi fertilitas yaitu perbandingan jantan dan betina, umur induk, lama penyimpanan telur tetas dan pengelolaan telur (Ensminger 1992). Rasio kawin alami jantan cihateup dan betina alabio

Tabel 1 Bobot telur itik CA

\begin{tabular}{lcccc}
\hline Periode penetasan & \multicolumn{3}{c}{ Waktu dimulainya pendinginan } & \multirow{2}{*}{ Rataan \pm SD } \\
\cline { 2 - 4 } & \multicolumn{1}{c}{ H3 } & H10 & H17 \\
\hline 1 & - & $66,49 \pm 4,92$ & $68,26 \pm 5,47$ & $66,8 \pm 5,44$ \\
2 & $69 \pm 4,57$ & $70,77 \pm 5,42$ & $70,21 \pm 4,22$ & $70,44 \pm 4,79$ \\
3 & $68,53 \pm 3,18$ & $68,43 \pm 4,44$ & $69,46 \pm 4,81$ & $69,17 \pm 4,25$ \\
4 & $68,71 \pm 4,99$ & $68,99 \pm 5,04$ & $71,06 \pm 6,36$ & $69,66 \pm 5,26$ \\
5 & $68,63 \pm 4,4$ & $68,59 \pm 4,43$ & $70,06 \pm 4,63$ & $68,74 \pm 4,71$ \\
\hline Rataan \pm sd & $68,8 \pm 4,12$ & $68,5 \pm 5,01$ & $70,27 \pm 5,04$ & $69,21 \pm 4,81$ \\
\hline
\end{tabular}

Keterangan: Tanda (-) menunjukkan bahwa pengukuran tidak dilakukan. 
Tabel 2 Indeks telur itik CA

\begin{tabular}{lcccc}
\hline Periode penetasan & \multicolumn{3}{c}{ Waktu dimulainya pendinginan } & \multirow{2}{*}{ Rataan \pm sd } \\
\cline { 2 - 4 } & \multicolumn{1}{c}{ H3 } & H10 & H17 \\
\cline { 2 - 4 } & & $78,66 \pm 2,47$ & $77,9 \pm 2,03$ & $78,29 \pm 2,26$ \\
2 & $79,33 \pm 1,81$ & $78,61 \pm 2,84$ & $79,3 \pm 1,8$ & $79,07 \pm 2,22$ \\
3 & $78,66 \pm 2,08$ & $79,35 \pm 4,88$ & $77,7 \pm 2,39$ & $78,56 \pm 3,37$ \\
4 & $78,55 \pm 3,84$ & $77,61 \pm 3,23$ & $77,91 \pm 3,14$ & $78,02 \pm 3,4$ \\
5 & $78,95 \pm 1,74$ & $78,75 \pm 2,97$ & $79,2 \pm 3,73$ & $78,97 \pm 2,91$ \\
\hline Rataan \pm sd & $78,85 \pm 2,47$ & $78,62 \pm 3,49$ & $78,44 \pm 2,93$ & $78,63 \pm 3,01$ \\
\hline
\end{tabular}

Keterangan: Tanda (-) menunjukkan bahwa pengukuran tidak dilakukan.

Tabel 3 Fertilitas telur itik CA

\begin{tabular}{lcccc}
\hline Periode penetasan & \multicolumn{3}{c}{ Waktu dimulainya pendinginan } & \multirow{2}{*}{ Rataan \pm Sd } \\
\cline { 2 - 4 } & H3 & H10 & H17 \\
\cline { 2 - 4 } & & $(\%)$ & 100 & $100 \pm 0$ \\
2 & 100 & 100 & 100 & $100 \pm 0$ \\
3 & 94,29 & 100 & 94,29 & $93,34 \pm 1,65$ \\
4 & 96,55 & 91,43 & 100 & $91,95 \pm 11,08$ \\
5 & 94,59 & 79,31 & 86,49 & $90,18 \pm 4,1$ \\
\hline Rataan \pm sd & $96,36 \pm 2,63$ & $92,04 \pm 8,6$ & $96,15 \pm 5,94$ & $94,74 \pm 6,29$ \\
\hline
\end{tabular}

Keterangan: Tanda (-) menunjukkan bahwa pengukuran tidak dilakukan.

dengan rasio (4:15) pada penelitian ini cukup baik dalam pemeliharaan itik. Fertilitas telur CA pada penelitian Matitaputty (2012) sebesar 95,19\%.

Fertilitas telur masih tinggi pada induk alabio berumur sampai 19 bulan. Hal tersebut ditunjukkan dengan telur yang dihasilkan induk alabio berumur 18 bulan selama 5 minggu fertilitasnya masih di atas 90\% (Tabel 3). Fertilitas telur terus menurun pada periode penetasan selanjutnya karena umur induk yang digunakan semakin tua.

Telur CA dikumpulkan dan disimpan kurang dari 7 hari sebelum ditetaskan. Fertilitas telur tinggi masih diperoleh pada penyimpanan selama kurang dari 1 minggu dan pengelolaan telur yang baik. Lama penyimpanan telur sebelum ditetaskan sebaiknya tidak lebih dari 7 hari. Penyimpanan telur yang semakin lama dapat berpengaruh terhadap fertilitas dan menurunkan daya tetas (Setioko 1998).

\section{Daya Tetas}

Itik betina alabio yang digunakan pada penelitian ini berumur 1,5 tahun dan dikawinkan alami dengan jantan cihateup berumur 1 tahun diharapkan dapat menghasilkan telur CA yang baik untuk ditetaskan. Penetasan telur itik selama 28 hari berbeda dengan telur ayam yang hanya 21 hari. Perbedaan tersebut mempengaruhi perkembangan embrio yang akan menghasilkan panas metabolisme semakin meningkat selama proses penetasan.

Kelebihan panas yang dihasilkan proses metabolisme embrio ditambah dengan akumulasi panas dan banyaknya telur berada di dalam mesin tetas dapat menyebabkan stres panas pada embrio, sehingga meningkatkan risiko kematian embrio dan menurunkan daya tetas telur itik. Rendahnya daya tetas dapat terjadi karena stres panas metabolisme akibat aktivitas pertumbuhan embrio (Harun et al. 2001).

Pendinginan pada waktu mulai yang berbeda tidak mempengaruhi daya tetas (Tabel 4). Daya tetas pada penelitian Matitaputty (2012) sebesar 61\%. Pendinginan di awal penetasan yaitu hari ke-3 memiliki daya tetas rendah karena embrio belum mampu memproduksi panas sendiri. Telur pada penetasan buatan membutuhkan panas dari mesin tetas untuk perkembangan normal embrio.

Pendinginan pada hari ke-10 atau 17 menghasilkan daya tetas yang lebih tinggi. Pendinginan yang diberikan menjelang akhir penetasan lebih bermanfaat mengatasi stres panas akibat akumulasi panas di dalam mesin tetas dan produksi panas metabolisme dari jumlah telur yang ditetaskan. Produksi panas sudah dihasilkan di akhir penetasan karena meningkatnya perkembangan embrio dan metabolisme di dalam telur. Tingginya resiko kematian embrio yang lambat menetas dan rendahnya daya tetas terjadi pada hari ke-18 penetasan. Hal tersebut disebabkan produksi panas embrio meningkat mencapai lebih dari $39^{\circ} \mathrm{C}$ (Lourens 2001).

Temperatur mesin tetas pada periode setter dalam penelitian ini berada dikisaran $37-38{ }^{\circ} \mathrm{C}$ (Tabel 5). Temperatur optimum penetasan itik untuk menghasilkan daya tetas tinggi adalah $38-39{ }^{\circ} \mathrm{C}$ (Ningtyas et al. 2013). Temperatur dan kelembaban mesin penetasan yang lebih rendah maupun lebih tinggi akan menghasilkan daya tetas rendah. Temperatur mesin yang disarankan untuk penetasan telur itik pada periode setter yaitu $37,3{ }^{\circ} \mathrm{C}$ dan $36,9{ }^{\circ} \mathrm{C}$ pada periode hatcher. Temperatur yang lebih rendah atau tinggi 
Tabel 4 Daya tetas telur itik CA

\begin{tabular}{lccc}
\hline \multirow{2}{*}{$\begin{array}{l}\text { Periode } \\
\text { penetasan }\end{array}$} & \multicolumn{3}{c}{ Waktu dimulainya pendinginan } \\
\cline { 2 - 4 } & $\mathrm{H} 3$ & $\mathrm{H} 10$ & $\mathrm{H} 17$ \\
\cline { 2 - 4 } & \multicolumn{3}{c}{$(\%)$} \\
\hline 1 & - & 46,67 & 71,43 \\
2 & 58,33 & 68 & 72,73 \\
3 & 69,7 & 65,63 & 57,58 \\
4 & 42,86 & 47,83 & 58,62 \\
5 & 68,57 & 73,53 & 62,5 \\
\hline Rataan \pm sd & $59,86 \pm 12,44$ & $60,33 \pm 12,29$ & $64,57 \pm 7,11$
\end{tabular}

Keterangan: Tanda (-) menunjukkan bahwa pengukuran tidak dilakukan

Tabel 5 Temperatur dan kelembaban mesin tetas

\begin{tabular}{lcccc}
\hline \multirow{2}{*}{$\begin{array}{l}\text { Periode } \\
\text { penetasan }\end{array}$} & \multicolumn{2}{c}{ Temperatur $\left({ }^{\circ} \mathrm{C}\right)$} & \multicolumn{2}{c}{ Kelembaban $(\%)$} \\
\cline { 2 - 5 } & Setter & Hatcher & Setter & Hatcher \\
\hline 1 & $37,8 \pm 1,16$ & $37,4 \pm 0,35$ & $56-65$ & $70-87$ \\
2 & $37,4 \pm 0,72$ & $37,5 \pm 0,79$ & $56-72$ & $70-87$ \\
3 & $37,1 \pm 0,32$ & $37,4 \pm 0,46$ & $63-72$ & $63-70$ \\
4 & $37,2 \pm 0,33$ & $37,2 \pm 0,15$ & $63-72$ & $60-70$ \\
5 & $37,4 \pm 0,3$ & $36,3 \pm 0,76$ & $63-72$ & $69-78$ \\
\hline
\end{tabular}

dari kisaran optimum akan mengganggu perkembangan normal embrio dan menyebabkan penguapan berlebih pada telur, sehingga menurunkan daya tetas. Secara umum suhu terlalu tinggi memiliki efek lebih buruk terhadap daya tetas daripada suhu yang terlalu rendah. Temperatur mesin tetas yang lebih tinggi $0,5{ }^{\circ} \mathrm{C}$ selama 3 hari dapat mengurangi daya tetas telur sampai 50\% dari yang diharapkan (Kortlang 1985).

Temperatur dan kelembaban setter dan hatcher yang lebih rendah daripada Matitaputty (2012), yaitu temperatur periode setter $38-39{ }^{\circ} \mathrm{C}$ dan kelembaban $65 \%$ $66 \%$, sedangkan hatcher sekitar $36{ }^{\circ} \mathrm{C}$ dengan kelembaban $85 \%-87 \%$ diduga menye-babkan daya tetas yang diperoleh lebih rendah. Kelembaban mesin tetas sebaiknya ditingkatkan mencapai 90\%-94\% dan temperatur $1{ }^{\circ} \mathrm{C}$ lebih rendah pada periode hatcher (Kortlang 1985). Kelembaban udara di akhir penetasan harus lebih tinggi bertujuan menjaga cairan dalam telur dan merapuhkan kerabang telur (Ningtyas et al. 2013).

\section{Bobot Tetas}

Bobot tetas diperoleh dari bobot DOD yang berhasil menetas dan ditimbang setelah bulunya kering. Persen bobot tetas DOD pada penelitian ini merupakan perbandingan bobot tetas dengan bobot awal telur.

Bobot tetas yang diperoleh pada perlakuan H17 lebih berat $(\mathrm{P}<0,05)$ daripada $\mathrm{H} 3$, namun tidak berbeda dengan H10. Perlakuan H17 memiliki bobot tetas 44,81 $\pm 3,99$ g diperoleh dari rataan bobot telur yang lebih besar, yaitu 70,27 $\pm 5,04 \mathrm{~g}$ (Tabel 1). Bobot telur sangat berpengaruh terhadap bobot tetas dan terdapat korelasi positif antara keduanya. Semakin berat bobot awal telur tetas akan dihasilkan bobot tetas lebih besar (Ismoyowati et al. 2006).

Proses penguapan yang terjadi di dalam telur dengan perlakuan pendinginan awal, tengah maupun akhir penetasan tidak berbeda. Persentase bobot tetas tidak menunjukkan adanya perbedaan nyata pada perlakuan yang berbeda. Persentase bobot tetas yang diperoleh pada penelitian ini berkisar antara 62.65\%-63.75\%. Produksi panas lebih dipengaruhi oleh tahapan perkembangan embrio (Meijerhof 2009).

\section{Kematian Embrio}

Kematian embrio telur CA pada penelitian ini dapat dihitung dari 100\% dikurangi daya tetas (Tabel 4). Kematian embrio pada umur telur berbeda selama penetasan dapat dilihat pada Gambar 1. Kematian embrio dapat dikelompokkan menjadi 3 yaitu awal (0-7 hari), tengah (825 hari) dan akhir saat telur berada di hatcher ( $>25$ hari) (Gambar 1). Persentase kematian embrio pada periode awal penetasan baik pada perlakuan H3, H10 maupun H17 lebih rendah selama proses penetasan. Kematian di awal penetasan umumnya terlihat pada kuning telur belum terbentuk pembuluh darah atau hanya sedikit dan tidak menyebar banyak. Kematian di awal penetasan umumnya disebabkan kondisi dan lama penyim-panan telur, sperma jantan dan umur induk betina (Setioko 2005).

Kematian embrio itik CA pada penelitian ini dapat terjadi karena stres panas metabolisme akibat aktivitas pertumbuhan embrio (Harun et al. 2001). Kematian embrio pada periode tengah lebih tinggi daripada di awal atau di akhir penetasan. Embrio yang semakin berkembang akan meningkat-kan resiko terjadinya stres panas akibat akumulasi panas yang dihasilkan dari aktivitas metabolisme embrio dan mesin tetas. Produksi panas mencapai fase stabil antara hari $15-18$ penetasan dan kira-kira $140 \mathrm{~mW}$ pada hari ke-18 penetasan untuk satu telur berukuran $62 \mathrm{~g}$ (Lourens et al. 2007).

Kematian embrio pada perlakuan pendinginan hari ke-3 lebih tinggi saat 8-25 hari penetasan (Gambar 1). Embrio pada awal penetasan membutuhkan panas untuk dapat berkembang secara normal, sehingga pendinginan yang diberikan lebih cepat akan mengganggu perkembangan embrio dan memiliki tingkat kematian lebih tinggi daripada pendinginan yang dilakukan di hari ke-10 atau 17 penetasan. Embrio muda belum mampu memproduksi panas hasil

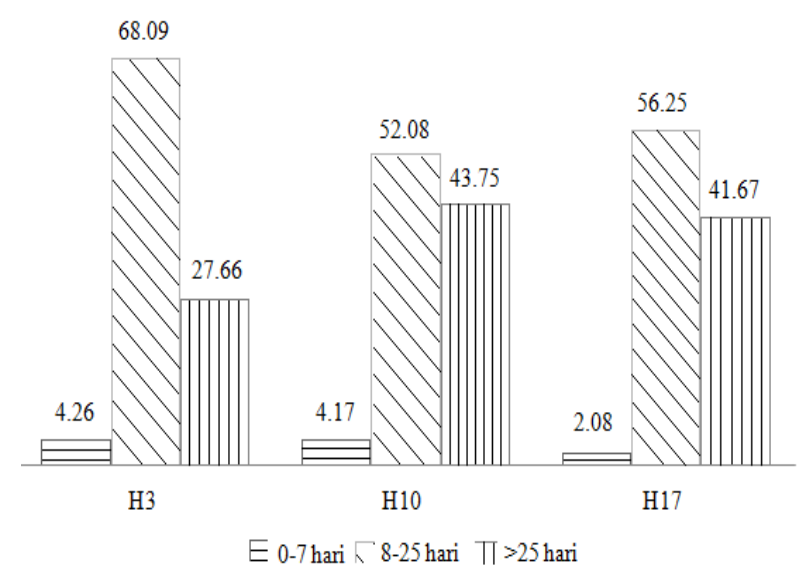

Gambar 1 Kematian embrio (\%) berdasarkan perlakuan pada umur telur berbeda 
Tabel 6 Bobot tetas dan persentase bobot tetas telur itik CA

\begin{tabular}{|c|c|c|c|}
\hline \multirow{3}{*}{$\begin{array}{l}\text { Periode } \\
\text { penetasan }\end{array}$} & \multicolumn{3}{|c|}{ Waktu dimulainya pendinginan } \\
\hline & $\mathrm{H} 3$ & $\mathrm{H} 10$ & H17 \\
\hline & \multicolumn{3}{|c|}{ Bobot tetas $(\mathrm{g})$} \\
\hline 1 & - & $41,56 \pm 4,79$ & $43,61 \pm 4,03$ \\
\hline 2 & $42,97 \pm 3,93$ & $45,2 \pm 4,4$ & $44,64 \pm 3,17$ \\
\hline 3 & $43,32 \pm 3,24$ & $42,62 \pm 3,53$ & $44,78 \pm 3,89$ \\
\hline 4 & $41,95 \pm 2,7$ & $44,61 \pm 6,24$ & $45,53 \pm 4,99$ \\
\hline 5 & $43,56 \pm 3,81$ & $43,39 \pm 3,28$ & $44,96 \pm 3,94$ \\
\hline \multirow[t]{2}{*}{ Rataan \pm sd } & $43,11 \pm 3,47 \mathrm{a}$ & $43,58 \pm 4,26 \mathrm{ab}$ & $44,81 \pm 3,99 \mathrm{~b}$ \\
\hline & \multicolumn{3}{|c|}{ Bobot tetas $(\%)$} \\
\hline 1 & - & $63,16 \pm 2,01$ & $64,53 \pm 3,53$ \\
\hline 2 & $62,09 \pm 3,43$ & $63,63 \pm 4,76$ & $63,05 \pm 3,02$ \\
\hline 3 & $62,84 \pm 3,04$ & $62,83 \pm 4,04$ & $63,11 \pm 2,7$ \\
\hline 4 & $62,27 \pm 2,98$ & $63,94 \pm 4,54$ & $63,7 \pm 2,16$ \\
\hline 5 & $62,97 \pm 3,57$ & $64,25 \pm 4,24$ & $64,57 \pm 3,07$ \\
\hline Rataan \pm sd & $62,65 \pm 3,24$ & $63,62 \pm 4,15$ & $63,75 \pm 2,88$ \\
\hline
\end{tabular}

Keterangan: angka yang diikuti huruf yang berbeda pada baris yang sama menunjukkan perbedaan yang nyata $(\mathrm{P}<0,05)$, Tanda (-) menunjukkan bahwa pengukuran tidak dilakukan

proses metabolisme yang cukup, jadi sangat bergantung dengan temperatur mesin tetas dan lebih sensitif terhadap perubahan temperatur daripada embrio tua (Setioko 1998).

Kematian embrio periode tengah lebih rendah pada pendinginan hari ke-10 dan 17 karena lebih bermanfaat mengatasi panas yang meningkat dibandingkan sejak awal penetasan. Pendinginan pada hari ke-17 penetasan memiliki tingkat kematian embrio yang sedikit lebih tinggi karena produksi panas sudah dihasilkan sejak telur berada sekitar 9 hari dalam penetasan, namun sudah cukup baik dalam mengatasi akumulasi panas yang dihasilkan embrio dan akumulasi di dalam mesin tetas. Hal tersebut ditunjukkan dengan kematian embrio 35,43\% pada pendinginan hari ke17 (Tabel 4). Kematian embrio pada penelitian Matitaputty (2012) sebesar 39\%. Tahapan awal produksi panas meningkat secara eksponen setelah 9 hari penetasan pada embrio ayam (Lourens et al. 2007). Sekitar hari ke-19 penetasan, setelah pipping bagian dalam, embrio akan berganti pernapasan paru-paru dan akibatnya produksi panas akan meningkat hampir 2 kali lipat pada embrio broiler (Janke et al. 2004).

Titik kritis proses penetasan terdapat di akhir perkembangan embrio yang disebut dengan gagal tetas. Gagal tetas pada penelitian ini ditandai dengan banyaknya embrio yang tidak berhasil menetas sempurna atau kesulitan keluar dari dalam kerabang telur. Kelembaban mesin tetas yang rendah pada periode hatcher diduga menyebabkan banyak embrio yang mati pada akhir penetasan (Tabel 5). Penyebab gagal tetas dalam proses penetasan terutama terjadi pada akhir masa penetasan dan disebabkan pengeringan selaput telur dalam pertumbuhan embrio yang tidak sempurna, sehingga embrio tidak dapat menetas dan masih terdapat dalam kerabang telur (Setiadi 2000).

\section{KESIMPULAN}

Pendinginan telur pada waktu mulai yang berbeda selama penetasan tidak berpengaruh terhadap daya tetas, tetapi diperoleh daya tetas tertinggi pada hari ke-17. Pendinginan telur pada akhir penetasan dapat meningkatkan bobot tetas.

\section{DAFTAR PUSTAKA}

[DPKH] Direktorat Jenderal Peternakan dan Kesehatan Hewan. 2012. Statistik Peternakan dan Kesehatan Hewan. Jakarta (ID): Direktorat Jenderal Peternakan dan Kesehatan Hewan Kementrian Pertanian.

Ensminger ME. 1992. Poultry Science. Ed ke-5. Illionis (US): Cab International.

Harun MAS, Veeneklaas RJ, Visser MGH, Van Kampen. 2001. Artificial incubation of Muscovy Duck eggs: why some eggs hatch and others do not. Poult Sci. 80:219-224.

Ismoyowati TY, Sidadolog JPH, Keman S. 2006. Hubungan antara karakteristik morfologi dan performans reproduksi itik tegal sebagai dasar seleksi. J.Indon. Trop.Anim. Agric. 31(3).

Janke O, Tzschentke B, Boerjan M. 2004. Comparative investigations of heat production and body temperature in embryo of modern chicken breeds. Avian Poult Bio. Rev. 15:191-196.

Ketaren PP, Prasetyo LH. 2002. Pengaruh pemberian pakan terbatas produktivitas itik silang mojosari $\mathrm{x}$ alabio (MA): 1. Masa bertelur fase pertama umur 2043 minggu. JITV. 7(1).

Kortlang CFHF. 1985. The Incubation of Duck Egg. In : Duck Production Science and World Practice. Farrel, DJ dan Stapleton P. Editor. University of New England, pp. 168-177.

Lourens A, Van den Brand H, Heetkamp MJW, Meijerhof R, Kemp B. 2007. Effects of eggshell temperature and oxygen concentration on embryo growth and metabolism during incubation. Poult Sci. 86:21942199.

Lourens A. 2001. The importance of air velocity in incubation. World Poult. 17(3):29-30.

Matitaputty PR. 2012. Peningkatan produksi karkas dan kualitas daging itik melalui persilangan antara itik Cihateup dengan itik Alabio [disertasi]. Bogor (ID):Institut Pertanian Bogor.

Mattjik AA, Sumertajaya IM. 2002. Perancangan Percobaan dengan Aplikasi SAS dan Minitab. Jilid 1. Ed ke-2. Bogor (ID): IPB Pr.

Meijerhof R. 2009. Incubation principles: What does the embryo expect from us? Proceedings of the 20 $0^{\text {th }}$ Australian Poultry Science Symposium. Sydney (AU). 106-110.

Ningtyas MS, Ismoyowati, Sulistyawan IH. 2013. Pengaruh temperatur terhadap daya tetas dan hasil tetas telur itik (Anas plathyrinchos). Jurnal Ilmiah Ternak. 1(1):347-352.

Nurcahyo EM, Widyastuti YE. 1997. Usaha Pembesaran 
Ayam Kampung Pedaging. Jakarta (ID): Penebar Swadaya.

Setiadi P. 2000. Pengaruh indeks bentuk telur terhadap persentase kematian embrio, gagal tetas dan DOD cacat pada telur itik tegal yang diseleksi. Anim Prod. 2(1).

Setioko AR. 1998. Penetasan telur itik di Indonesia. Wartazoa. 7(2).

Setioko AR. 2005. Fertilitas dan kematian embrio pada perkawinan silang entog jantan dan itik betina. Lokakarya Nasional Unggas Air II. Di dalam: Merebut peluang agribisnis melalui pengembangan usaha kecil dan menengah unggas air. Bogor, 16-17 November 2005. Ciawi. 271-280. 